\title{
Raíces latinoamericanas del otro desarrollo: estilos de desarrollo y desarrollo a escala humana
}

\section{Latin American Roots of the Other-Development: Development Styles and Human Scale Development Approach}

\author{
Rafael Domínguez \\ Universidad de Cantabria, Santander, España, \\ email: domingur@unican.es
}

\section{Sara Caria}

Instituto de Altos Estudios Nacionales IAEN, Quito, Ecuador, email: sara.caria@iaen.edu.ec

Resumen. El presente trabajo propone una reconstrucción histórica de las ideas sobre el desarrollo alternativo en América Latina, comprendido entre las décadas de 1960 y 1980, en el contexto de los debates internacionales en torno a los tres primeros decenios de la Organización de las Naciones Unidas, a fin de evaluar su conexión directa e indirecta con otras variantes actuales de estilos de desarrollo que han tomado fuerza en la región desde los inicios del siglo XxI (específicamente el Buen Vivir). La hipótesis sostenida es que dicha conexión es latente y se concluye que es necesario explicitarla a la hora de analizar estos estilos en la actualidad.

Palabras clave: estilos de desarrollo; desarrollo económico; ecodesarrollo; desarrollo humano; buen vivir.

Abstract. This work traces a historical reconstruction of Latin American ideas on development during the $60 \mathrm{~s}, 70 \mathrm{~s}$ and $80 \mathrm{~s}$, in the context of the first three decades of development of the United Nations. The aim is to establish their connection with other contemporary version or styles of development that have gained prominence since the beginning of the XXI century (specifically, Good Living). The hypothesis is that such connection exists and it is necessary to make it explicit when analyzing these new development styles.

Keywords: economic development; human development; eco-development; development styles; Good Living.

JEL: O15; N16. 
Fecha de recepción: 26 de junio de 2017. Fecha de aceptación: 1 de diciembre de 2017.

\section{INTRODUCCIÓN}

$\mathrm{C}$ n este trabajo se recupera el pensamiento sobre el desarrollo alternativo, u "otro desarrollo", que surgió entre América Latina y Europa como corriente intelectual en las décadas de los sesenta, setenta y ochenta, en el contexto de los debates internacionales en relación con los tres primeros decenios de desarrollo de la Organización de las Naciones Unidas (en adelante ONU). En concreto, se analizan las propuestas de desarrollo humano-céntrico (Seers, 1969), estilos de desarrollo (Centro de Desarrollo [en adelante CENDES], 1969), ecodesarrollo (Sachs, 1974a, 1974b, 1977 y 1980; Programa de las Naciones Unidas para el Medio Ambiente/ Conferencia de las Naciones Unidas sobre Comercio y Desarrollo [en adelante PNUMA/UNCTAD por sus siglas en inglés], 1974), otro desarrollo (Fundación Dag Hammarskjöld, 1975), desarrollo social y humano (Comisión Económica para América Latina [en adelante CEPAL], 1981), estilo de desarrollo alternativo (Sunkel, 1980) y desarrollo a escala humana (Max-Neef, Elizalde y Hopenhayn, 1986); esta última propuesta ha sido muy influida por el pensamiento original del español José Luis Sampedro, quien abrió el camino a los enfoques posdesarrollistas más debatidos: concretamente, lo que Hidalgo-Capitán (2012, pp. 27-28) ha denominado interpretaciones ecologista e indigenista del Buen Vivir.

El marco teórico-metodológico del trabajo es deudor de varias tradiciones sobre la historia de las ideas y la importancia de las propias ideas en la historia (el planteamiento dialéctico de Hegel y la sociología del conocimiento de Marx, pasados por el tamiz de Weber, Manhheim y Lovejoy), que, aplicadas a los temas que nos ocupan, se resumen en la siguiente afirmación: "las ideas son una fuerza impulsora en el progreso humano", lo que "no niega el papel del poder y de los intereses materiales, sino pone de relieve el papel de las ideas en ayudar a configurar intereses y restringir el ejercicio del poder en bruto" (Emmerij, Jolly y Weiss, 2005, p. 212). Si las ideas se definen como "creencias normativas o causales mantenidas por individuos o adoptadas por instituciones que influyen sus actitudes y acciones" (Emmerij, Jolly y Weiss, 2005, p. 214), proponemos una reconstrucción histórica de las ideas sobre el desarrollo alternativo en América Latina, a fin de evaluar su conexión directa e indirecta con otras variantes actuales de estilos de desarrollo, ${ }^{1}$ que han tomado fuerza en la región desde los ini-

${ }^{1}$ Según el director adjunto de la División de Desarrollo Social de la CEPAL, "un estilo es una especie de integración de las estrategias de desarrollo con los factores de poder que hacen posible 
cios del siglo XXI, en particular, la interpretación socialista del Buen Vivir (Hidalgo-Capitán, 2012, pp. 27-28) y su concreción en política pública. ${ }^{2}$ La hipótesis sostenida es que dicha conexión es latente y se concluye que es necesario explicitarla a la hora de analizar estos estilos en la actualidad.

Hechas estas precisiones, el artículo se organiza en tres apartados siguiendo la cronología de las tres primeras décadas del desarrollo de la ONU. En las consideraciones finales se valora la necesidad de analizar el pensamiento latinoamericano sobre el desarrollo alternativo desde la perspectiva de historia de las ideas o de la reconstrucción histórica del pensamiento económico.

\section{PRIMERA DÉCADA: DEL SIGNIFICADO A LOS ESTILOS DEL DESARROLLO}

\section{El destronamiento del producto nacional bruto como indicador del desarrollo}

Lanzada en diciembre de 1961 mediante la Resolución 1710 (XVI), a partir de una idea original del presidente Kennedy, la "década del desarrollo de Naciones Unidas" llegó al final de su trayecto en un ambiente de decepción entre los creyentes en la ideología del desarrollo. Pese a que en 1962 el Ecosoc (United Nations Economic and Social Council) había recomendado la integración de los aspectos económicos y sociales del desarrollo, pese a que la estrategia para la década afirmaba que "el objetivo último del desarrollo económico es el progreso social" (Department of Economic and Social Affairs, 1962, p. 7), pese a la creación en 1964 del UNRISD (Instituto de Investigación de las Naciones Unidas para el Desarrollo Social, por sus siglas en inglés) y pese al dinamismo dado por el presidente del Comité de Planificación del Desarrollo del Ecosoc, ${ }^{3}$ los aspectos sociales y económi-

su realización en un sistema económico y social históricamente determinado, y orientado hacia ciertos objetivos" (Graciarena, 1976, p. 186).

${ }^{2}$ El Buen Vivir fue el lema inspirador de las políticas públicas de la Revolución Ciudadana desde su incorporación en la nueva Constitución de Ecuador en 2008, que contiene un capítulo específico sobre el Régimen del Buen Vivir como triple armonía con uno mismo, los demás y la naturaleza. En los dos Planes Nacionales de Desarrollo, denominados Planes Nacionales para el Buen Vivir, de 2009-2013 y 2013-2017, se intenta instrumentar dicho régimen en un programa de políticas públicas que inicialmente pretendió lograr en forma simultánea los objetivos de la armonía con la naturaleza, el respeto de la plurinacionalidad, la satisfacción de las necesidades básicas, la justicia social e igualdad, y la democracia participativa (Caria y Domínguez, 2014). En el núcleo del programa económico estuvo la idea del cambio de la matriz productiva, distributiva y de conocimiento (cambio estructural ligado a la redistribución estática y dinámica, esta última con fuerte gasto público en educación), y una estrategia de crecimiento intensiva en la creación de empleo (León y Domínguez, 2017; Minteguiaga y Ubasart, 2015; Weisbrot, Johnston y Merling, 2017).

${ }^{3}$ Se trata del gran economista socialdemócrata holandés Jan Tinbergen, que fue nombrado en 1965 para ese puesto por sus ideas sobre la planificación centralizada y la convergencia del ingreso a escala mundial. 
cos del desarrollo acabaron siendo tratados por separado (Jolly, Emmerij, Ghai y Lapeyre, 2009).

Es cierto que la modesta y única meta cuantificable de la década ("un ritmo mínimo anual de crecimiento del 5\% en el ingreso nacional") se logró con un crecimiento de la población de 2.5\% anual de los países en desarrollo, y se alcanzó un aumento de 3.5\% del ingreso per cápita entre 1961 y 1970. Pero la segunda parte del objetivo general de la Resolución 1710 (XVI), ${ }^{4}$ referida al "progreso social", fracasó en la mayoría de los países (Jolly et al., 2009, p. 107). Ello detonó el debate sobre el "significado del desarrollo", que se cristalizó en el título del famoso ensayo escrito por Dudley Seers en 1969, y en el que se cuestiona la idea del desarrollo entendido como crecimiento.

La conexión latinoamericana de Seers como pionero del desarrollo ${ }^{5}$ fue fundamental. Seers no sólo construyó la nueva disciplina del desarrollo económico a través de su maestra Joan Robinson (quien integró el pensamiento de Marx y Keynes y la síntesis de ambos realizada por el economista marxista Michal Kalecki), sino que también fue muy influido por el estructuralismo de Raúl Prebisch, quien tuvo una profunda ascendencia keynesiana (Pérez-Caldentey y Vernengo, 2016, pp. 1725 y 1729). Tras su breve interregno en Nueva York, Seers ingresó en 1957 a la CEPAL, donde trabajó hasta 1961 y, a las órdenes de Raúl Prebisch y Osvaldo Sunkel, se convirtió en un estructuralista convencido.

En su famoso ensayo de 1969, y reeditado tan sólo un año después en la Revista Brasileira de Economia en portugués e inglés, lanzó un ataque devastador contra el producto nacional bruto (en adelante, PNB) como medida del desarrollo. Seers llamó la atención sobre la falta de rigor que suponía identificar crecimiento económico con desarrollo económico o, dicho de otra manera, creer que el aumento del PNB a mayor velocidad que el aumento de la población "más pronto o más tarde lleva a la solución de los problemas sociales y políticos" (Seers, 1969, p. 1). Para Seers, el desarrollo debía ser un "concepto normativo, casi como un sinónimo de mejora", que él identifica no con "copiar las vías al desarrollo de otros países" a la Rostow, sino con el establecimiento de "las condiciones necesarias para

\footnotetext{
${ }^{4}$ Véase la Resolución 1710 (XVI), United Nations Development Decade. A programme for international economic co-operation, de 19 de diciembre de 1961, disponible en http://www. un.org/Docs/journal/asp/ws.asp?m=A/RES/1710(XVI).

${ }_{5}^{5}$ Seers, como discípulo de Joan Robinson, presidió la Sociedad Marxista de Cambridge, luego trabajó bajo las órdenes de Michal Kalecki entre 1953 y 1955, durante su paso por el Departamento de Asuntos Económicos y Sociales de la ONU y, tras su paso por la CEPAL, fundó uno de los primeros institutos de desarrollo (el IDS: Institute of Development Studies de la Universidad de Sussex) en 1966, rompiendo con la línea característica de los centros de Estados Unidos, creados previamente para investigar el crecimiento económico. El IDs luego asesoró, a instancias de Seers, al gobierno socialista de Salvador Allende.
} 
un propósito universalmente aceptable, la realización del potencial de la personalidad humana" (Seers, 1969, pp. 2-3). Esto implicaba atender tres elementos: 1) la satisfacción de las "necesidades básicas" de alimentación, vestido y vivienda (elemento de pobreza); 2) el trabajo como "algo sin lo que la personalidad no puede desarrollarse" (empleo), y 3) la "igualdad", que "debería ser considerada un objetivo en sí misma" (Seers, 1969, pp. $4-5) .{ }^{6}$ La conclusión era que si estos tres "problemas centrales" se atenúan, se puede hablar de desarrollo; pero si uno, dos o los tres han empeorado, "sería extraño llamar al resultado desarrollo, incluso si el ingreso per cápita se duplicara" (Seers, 1969, p. 5).

A continuación, Seers analiza la "consistencia interna del proceso de desarrollo" (Seers, 1969, pp. 16-17), concentrándose en la desigualdad como "principal obstáculo al desarrollo" por el lado de la demanda y la oferta: en países que sufren de estrangulamientos en su balanza por cuenta corriente, los ricos tienden a elevadas propensiones, "no meramente al gasto, sino al gasto en bienes y servicios con alto contenido en divisas", y en esos países resulta cuestionable que la producción pueda aumentar rápidamente con una fuerza laboral "muy mal alimentada para el trabajo manual y mental" si la desigualdad impide la cooperación de los trabajadores con el gobierno para la moderación de los aumentos salariales y desmoviliza las energías sociales necesarias para romper las instituciones que obstruyen el desarrollo en las zonas rurales (Seers, 1969, p. 18).

En definitiva, Seers expone en este ensayo, el primero sobre "el destronamiento del PNB" (Arndt, 1989, p. 99), una idea de desarrollo que mezcla dos ingredientes complementarios: el trabajo como actividad creativa propia de la esencia humana de Marx y Veblen y el principio comunitario igualitarista de Ghandi. El primero está en la base del concepto marxista de alienación; el desarrollo humano, es decir "el desarrollo de los individuos en todos sus aspectos" (Marx, 1979, p. 18), es donde hay que buscar la centralidad del socialismo humanista de la crítica de Seers, que, como la de Marx, es de raíz aristotélica y por ello se centra en la diferencia entre ser y tener o "completo desarrollo de todo el potencial humano" (Lebowitz, 2009). Sin embargo, esa diferencia es también el prólogo de la crítica de Veblen al consumo conspicuo de la clase rica ociosa y de la identificación de la emulación pecuniaria (el consumismo basado en la imitación de las pautas de consumo ostentoso de los ricos) como "el más fuerte, el más aler-

\footnotetext{
${ }^{6}$ Seers añade que "la realización del potencial humano" requiere otros elementos que no se pueden especificar en términos económicos, como "niveles adecuados de educación, libertad de expresión, la ciudadanía de una nación que sea verdaderamente independiente, tanto económica como políticamente, en el sentido de que las visiones de otros gobiernos no predeterminen en gran parte sus propias decisiones de gobierno". Esto último es el elemento internacional que luego retomarán los partidarios del otro desarrollo.
} 
ta y persistente de los motivos propiamente económicos" (Veblen, 2007, p. 75). Vale señalar que esta última crítica, presente en los primeros trabajos de Cardoso (1961, p. 109) o en las consideraciones de Prebisch (1961, p. 12) sobre "el consumo excesivo de los grupos de altos ingresos de los países latinoamericanos", será recuperada por Seers y luego por los partidarios del enfoque del ecodesarrollo.

El segundo ingrediente de la idea de desarrollo de Seers es la visión "humano-céntrica" del pensamiento ético de Ghandi sobre el desarrollo, derivada de su enfoque comunitario igualitarista o grassroot (Gosh, 2012, p. 182). Revindicando el "bienestar para todos", Ghandi conecta el bienestar individual con el bienestar de la comunidad, y la igualdad en la satisfacción de las necesidades básicas con su temprana crítica al consumismo como punto de partida para la autorrealización personal (Singh, 2006). Es más, "el ideal de sentido común" de la economía neoclásica según el cual "la beatitud económica reside en el consumo irrestricto de bienes sin trabajo" (Veblen, 1898, p. 187), es justo uno de los "Siete pecados sociales" ("Riqueza sin trabajo") que Ghandi recomienda evitar (Singh, 2006, p. 107) y que conecta con el pensamiento cepalino sobre la conexión deletérea desigualdad-crecimiento y la cuestión de los límites internos por parte del ecodesarrollo de Sachs (Estudos Avançados, 2004, p. 358).

Seers, muy influido por el pensamiento estructuralista latinoamericano, compartió estas reflexiones con sus colegas de la CEPAL, donde el brasileño Celso Furtado le precedió en la crítica al desarrollo como ideología del crecimiento económico, y abrió así el camino que va del estructuralismo a la teoría de la dependencia.

\section{La conexión latinoamericana: ideología y estilos de desarrollo}

En efecto, el desarrollo se contempló en la década de 1960 en América Latina como una ideología movilizadora (Max-Neef, Elizalde y Hopenhayn, 1986 , p. 11), pero también como una ideología en el sentido peyorativo que Marx había atribuido a las categorías de la economía política clásica en tanto que representación invertida de la realidad, ideología que legitimaba los intereses de la clase dominante y que no era operativa fuera del contexto en el que se había creado (el de los países capitalistas desarrollados, o centrales en la terminología de la CEPAL): "mientras el desarrollo, en la modalidad del capitalismo clásico, creó condiciones de estabilidad social y abrió las puertas al reformismo, la situación de los países latinoamericanos es fundamentalmente diversa", afirmó el brasileño Celso Furtado (1966, p. 
387) desde la CEPAL, ${ }^{7}$ que, como comisión regional de la ONU, sirvió para difundir "un conjunto de creencias, principios y actitudes, en breve una ideología" (la teoría estructuralista) que para inicios de la década de 1960 ya era "altamente influyente entre los intelectuales y los policymakers de América Latina" (Hirschman, 1961, p. 13).

La CEPAL había tomado nota del pensamiento de Gandhi cuando publicó en su boletín un documento sobre el "desarrollo comunitario en relación con la aceleración del desarrollo económico y social”, en el que se preguntaba si un elemento similar al gandhismo "podría crear la atmósfera de movilización de las fuerzas nacionales y la construcción nacional" en los países de América Latina (Economic Commission for Latin America [en adelante ECLA], 1964, pp. 232 y 255). Y la respuesta la dio Furtado, "primer teórico de la dependencia" (Love, 1994, p. 438), en su artículo sobre la ideología del desarrollo, previo al ensayo de Seers. Furtado, que fue ministro de Planificación (1962-1963) durante el gobierno de João Goulart con el Partido de los Trabajadores, muestra que en América Latina el progreso técnico lleva a la inestabilidad social e impide "el perfeccionamiento gradual de las instituciones políticas", mientras que la trasposición directa de las ideologías europeas (liberalismo y socialismo) en ese contexto de "masas urbanas heterogéneas que están ascendiendo en la conciencia política" introdujo rigideces adicionales que explican la deriva populista de los movimientos de masas (Furtado, 1966, pp. 388 y 390-391). La conclusión de Furtado es que había que dar la vuelta al desarrollo para convertirlo en la ideología socialista movilizadora basada en la recuperación "progresiva de la capacidad de autodeterminación": "la sustancia ideológica del socialismo latinoamericano será seguramente extraída de la conciencia crítica formada en la lucha por superar el subdesarrollo", lucha que "está provocando la transformación de la vasta comunidad de pueblos que constituyen el Tercer Mundo" (Furtado, 1966, p. 391). Así, con Furtado, los componentes humanista y comunitario de las primeras críticas al desarrollo fueron precedidos por el componente internacionalista de este "primer teórico de la dependencia" (Love, 1994, p. 438).

Furtado no había analizado en su trabajo el contenido económico del proceso de desarrollo, sino tan sólo sus resultados en términos de estabilidad social y política. Fue el argentino Óscar Varsavsky, desde el Grupo de modelos matemáticos del Centro de Desarrollo (en adelante CendEs) de la Universidad Central de Venezuela, fundado en 1961, antes que el IDS, el que exploró el tema de los "estilos de desarrollo" partiendo del desarrollo como proceso de cambio estructural (CENDES, 1969). El cambio estructu-

\footnotetext{
${ }^{7}$ Furtado, fue, junto con Prebisch y Seers, el tercero de los "pioneros" cepalinos del desarrollo, al haberse unido a la CEPAL desde el momento de su fundación en 1949.
} 
ral se definía como la transformación de la estructura productiva (industrialización) y la modificación de la composición de la demanda agregada. Se trataba de analizar, por tanto, las "diferentes maneras de cambiar la estructura actual del producto y la demanda, junto con las demás variables económicas a ellos vinculadas" (CENDES, 1969, p. 518). Varsavski y sus colaboradores del CENDES simularon matemáticamente tres estilos de desarrollo ("consumista", "autoritario" y "creativo"), asimilables a "tres ideologías, filosofías, [o] imágenes de la sociedad" y pusieron en "primer plano" los "aspectos cualitativos" (CENDES, 1969, pp. 518-519).

De los tres estilos, resulta pertinente para nuestro propósito confrontar los dos más puros: el consumista (CONS) y el creativo (CREA). El estilo CONS o "modernista" buscaba "alcanzar a los países desarrollados" con una estrategia "seguidista" en términos de patrones de producción y consumo y de política económica, que más tarde o más temprano toparía con las limitaciones propias del proceso de industrialización por sustitución de importaciones dependiente de la inversión extranjera directa. Por su parte, el estilo CREA, "educativo" o de "cultura autónoma", daba prioridad al "desarrollo de la capacidad creadora y, por lo tanto, a la educación (convenientemente reformada)" a fin de fomentar la "gestación de una tecnología autónoma"; por tanto, desalentaba el "seguidismo a los países desarrollados" en las pautas de producción y "en particular, en cuanto al consumo", con mayor peso de la inversión pública en detrimento de la inversión directa extranjera y una "política impositiva muy dura y progresiva para poder financiar el coste de la educación, salud y otros servicios gratuitos" (CENDES, 1969, pp. 524-525). Dadas las premisas del estudio, definidas como "clásicos problemas del desarrollo" (CENDES, 1969, p. 517), ${ }^{8}$ Varsavski y sus colaboradores abogaron por el estilo creativo, ya que "genera mucho empleo, mejora la productividad del trabajo y del capital, no exige grandes importaciones, puede irse liberando del capital extranjero, $y$, por definición, es capaz de organizar la población de manera eficiente" (CENDES, 1969, p. 538). ${ }^{9}$ Los paralelismos entre CREA y los Planes Nacionales para el Buen Vivir (Caria y Domínguez, 2016, pp. 20-21) no parecen producto de la mera coincidencia, sino de la misma inspiración filosófica de orientación socialista.

8 “ $a$ ) capitalizarse sin endeudamiento externo; $b$ ) disponer de recursos humanos de la calidad necesaria; $c$ ) sin desempleo; $d$ ) conseguir que lo producido quede en el país (o se intercambie por otros bienes no producidos); y $e$ ) sea distribuido equitativamente entre sus habitantes" (CENDES, 1969, p. 517).

${ }^{9}$ En contraste, el estilo consumista "no es capaz de financiar un crecimiento igual al del CREA (e incluso menor en términos de ingreso nacional)". 
La Primera Década del Desarrollo cerró con la Resolución 2542 (XXIV) ${ }^{10}$ que aprobó la Declaración sobre el Desarrollo y el Progreso Social de diciembre de 1969. Este documento fue un reconocimiento de las críticas de Seers al PNB como indicador del desarrollo y su reivindicación humano-céntrica del enfoque ético del desarrollo, tomando nota de "la interdependencia del desarrollo económico y del desarrollo social en el proceso más amplio de crecimiento y cambio, y la importancia de una estrategia de desarrollo integrado que tenga plenamente en cuenta, en todas las etapas, sus aspectos sociales". En la misma línea, la Declaración -que, sin embargo, dejó de lado las críticas de Furtado sobre el mito del desarrollo como convergencia con los países industrializados y su propuesta socialista de superación del subdesarrollo-, reconocía "la urgente necesidad de reducir y eventualmente eliminar la disparidad entre el nivel de vida existente en los países más avanzados económicamente y el que impera en los países en desarrollo". Entre sus prioridades destacan la apuesta por la "eliminación de la pobreza", la "distribución justa y equitativa del ingreso" y el derecho a "un trabajo productivo y socialmente útil", libre de "cualesquiera formas de explotación del hombre", lo que demandaba reformas al derecho de propiedad (subordinándolo a la función social) y mayores estándares de higiene y salud laboral. En el plano internacional se hacía un llamamiento a "la eliminación de todas las formas de explotación económica extranjera" (monopolios internacionales expresamente incluidos), "a fin de permitir a los pueblos de todos los países el goce pleno de los beneficios de sus recursos nacionales". Además, se introdujo una alusión a "la protección y el mejoramiento del medio humano". La Resolución 2543 (XXIV) decidió tomar en cuenta todas estas consideraciones "en la formulación de la estrategia del Segundo Decenio de las Naciones Unidas para el Desarrollo y en la aplicación de los programas de acción internacional que se llevarán a cabo durante el Decenio". ${ }^{11}$

\section{SEGUNDA DÉCADA: DE LOS ESTILOS DE DESARROLLO AL OTRO DESARROLLO}

Los pobres resultados de la Primera Década del Desarrollo en los tres objetivos con los que Seers, tras su paso por la CEPAL, había resignificado el desarrollo (reducción de la pobreza, la desigualdad y el desempleo), además del aumento de la brecha en ingreso per cápita entre países desarrollados y en desarrollo que tuvo lugar durante ese decenio, determinaron las preocupaciones de la Segunda Década del Desarrollo. En ese momento el

\footnotetext{
${ }^{10}$ Véase el texto completo en http://www.un-documents.net/a24r2542.htm

${ }^{11}$ Véase el texto completo en http://www.worldlii.org/int/other/UNGA/1969/54.pdf
} 
pensamiento sobre el desarrollo se movió entre la radicalización (teoría de la dependencia, de ascendencia marxista) y la reforma (el Nuevo Orden Económico Internacional [en adelante NOEI], de ascendencia keynesiana) (Jolly et al., 2009, pp. 108 y 111). A ello se unieron dos crisis de naturaleza muy diferente y a las que puso nombre el mismo año (1971): la crisis ambiental y la segunda crisis de la teoría económica. La "crisis ambiental" es el término elegido para describir la creciente conciencia social sobre el daño producido en la ecósfera por el modelo de crecimiento económico capitalista (Commoner, 1971). Esta crisis, junto con el primer choque petrolífero (1973), hizo que el desarrollo (por antonomasia económico) se convirtiera en una palabra sucia, que precisaría de nuevas cualificaciones y ciertas estrategias transformistas para restaurar su antigua legitimidad (Rist, 2007).

Por su parte, la "segunda crisis de la teoría económica" (Robinson, 1971) fue el resultado de la aplicación distorsionada de la revolución keynesiana por parte del complejo militar-industrial. La preocupación genuina de Keynes (así como de la nueva disciplina de la economía del desarrollo de Tinbergen y los pioneros cepalinos como Prebisch o Seers) era la solución de lo que él había identificado como el "Problema Económico": la eliminación de la pobreza y la reducción de las desigualdades entre y dentro de los países (Keynes, 1931, p. VII). Sin embargo, los objetivos desarrollistas se subordinaron al gasto en armamento alimentado por la guerra fría (y otras calientes), así que el "agradable sueño" de Keynes se convirtió en una "horrible pesadilla" con la escalada de Vietnam (Robinson, 1971, p. 210). Lo que mejor resistió ese proceso de escamoteo del pensamiento keynesiano fue la esperanza de Keynes de que, cuando se lograra un cierto nivel material de vida (entre cuatro y ocho veces mayor que el de su tiempo), la gente podría dedicar sus "energías morales y materiales" a "cultivar en una perfección completa el arte de la vida", es decir, a "vivir sabiamente y agradablemente y bien" (Keynes, 1931, pp. VII y 267-268). Esta idea, que es el antecedente intelectualmente más prestigioso del Buen Vivir, ejerció una gran fascinación sobre los que, como Fritz Schumacher, acabarían impactando en el concepto de desarrollo a escala humana, aunque en un contexto muy diferente de cuestionamiento del papel del Estado.

La Resolución 2626 (xxv), en la que se adoptó la Estrategia Internacional de Desarrollo para la Segunda Década del Desarrollo de la ONU en octubre de $1970,{ }^{12}$ reflejó todas estas preocupaciones. La nueva década debía "ser un paso adelante en cuanto a asegurar el bienestar y la felicidad no sólo de la generación actual, sino también de las generaciones venideras", el desarrollo debía integrar las dimensiones económicas y sociales en

\footnotetext{
${ }^{12}$ Véase el texto completo en http://www.un-documents.net/a25r2626.htm
} 
el plano nacional y la reducción de las brechas (convergencia) de ingreso en el plano internacional: "la tasa media de crecimiento anual de producto bruto per cápita en los países en desarrollo considerados en conjunto deberá ser de alrededor del 3.5\% durante el Decenio, con la posibilidad de acelerarla durante la segunda mitad del Decenio, a fin de lograr por lo menos un modesto comienzo de reducción de la disparidad de nivel de vida entre los países desarrollados y en desarrollo".

En el plano discursivo, se planteaban dos nociones novedosas conectadas entre sí: una como metodología de integración o desarrollo "unificado" (desarrollo integral) de los aspectos económicos, sociales e internacionales; y otra como idea en acción ("desarrollo humano"), vinculada a la satisfacción de las necesidades básicas mediante "una distribución más equitativa del ingreso y de la riqueza", que acompasara al crecimiento económico

para promover la justicia social y la eficiencia de la producción, elevar sustancialmente el nivel de empleo, lograr un nivel más alto de seguridad de ingreso, ampliar y mejorar los medios de educación, sanidad, nutrición, vivienda y asistencia social, y salvaguardar el medio ambiente. Así, los cambios cualitativos y estructurales de la sociedad deben ir a la par del rápido crecimiento económico, y las diferencias existentes -regionales, sectoriales y sociales- deben reducirse sustancialmente. Estos objetivos son a la vez factores determinantes y resultados finales del desarrollo; deben ser considerados, por lo tanto, como partes integradas del mismo proceso dinámico y requieren un enfoque unificado. ${ }^{13}$

Pero el "desarrollo humano" en la Estrategia no es todavía el desarrollo de las capacidades que ya había intuido Seers, a partir del pensamiento de Marx, Veblen o Ghandi, sino una metáfora humanizada del desarrollo económico: así como el desarrollo económico requiere planificación, el desarrollo humano empieza por la planificación familiar y luego sigue con el desarrollo de los recursos humanos. Esto precisa programas de fomento del empleo y estándares laborales, programas educativos, de salud y nutrición, de acceso a la vivienda y dotación de infraestructuras comunitarias en áreas rurales y urbanas, además de "contener el deterioro del medio humano y adoptar medidas a fin de mejorarlo" y "fomentar las actividades que contribuyan a mantener el equilibrio ecológico, del cual depende la supervivencia de la humanidad". Si en la Primera Década del Desarrollo los aspectos sociales y económicos se trataron por separado, en la Segunda Década se buscó su integración, desde el momento de la aprobación de la Estrategia con su novedoso concepto de desarrollo humano. Para fines del decenio, sin embargo, el Banco Mundial ya había cooptado el desa-

${ }^{13}$ Véase el texto completo en http://www.un-documents.net/a25r2626.htm 
rrollo humano con el propósito de convertirlo en sinónimo de reducción de la pobreza con base en más crecimiento,${ }^{14}$ con lo que se falsificaban las prioridades del desarrollo de la ONU, a la vez que se desviaba la atención de las reclamaciones del NOEI (Lobo, 1983; Moreno, 1985; Pronk, 1978; Samater, 1984; Stewart, 2006).

Así, el Informe de Desarrollo Mundial de 1980 decidió pasar del "desarrollo de los recursos humanos" al "desarrollo humano para enfatizar que este es tanto un medio como un fin del desarrollo económico" (World Bank, 1980, p. 32). La agenda de las necesidades básicas sirvió para resignificar el desarrollo económico (cambio estructural mediante industrialización) como desarrollo humano (lucha contra la pobreza), lanzando una "cortina de humo" (Samater, 1984, p. 5) para distraer la atención de la enorme brecha en el nivel de transformación industrial entre países desarrollados y en desarrollo, y, de paso, preparar el relato de que la destrucción del medio ambiente era culpa de los pobres (Lobo, 1983).

Pero, justamente, el elevado nivel de industrialización empezó a ponerse en cuestión en los países desarrollados, donde algunos autores (Mishan, 1960, p. 194), llegaron a recomendar a los países en desarrollo que no aspiraran a esa "tierra del despilfarro de la Subutopía". Ese "no a la industrialización" antes de la industrialización recibió su respuesta desde los países subordinados de la periferia con el concepto de ecodesarrollo, promovido por el entorno académico y de publicaciones de la CEPAL.

\section{Ecodesarrollo y nuevo orden económico internacional}

El ecodesarrollo y la discusión sobre los estilos de desarrollo deben entenderse en el contexto de las actividades preparatorias para la Conferencia de Estocolmo sobre Medio Ambiente Humano (Estocolmo, 1972) y los debates sobre el NOEI. El término ecodesarrollo y su difusión internacional se debió al consultor Ignacy Sachs, con hondas raíces intelectuales en el pensamiento latinoamericano. ${ }^{15}$ Sachs formó parte del grupo de expertos

14 “el desarrollo humano -educación y formación, mejor salud y nutrición, y reducción de la fertilidad-se ha mostrado importante no sólo para el alivio de la pobreza directamente, sino también para incrementar los ingresos de los pobres, así como el crecimiento del PNB [...]. Mientras que ahora hay un creciente reconocimiento de que el crecimiento no obvia la necesidad de desarrollo humano y otras medidas para reducir pobreza, hay que subrayar que lo contrario es cierto también: las medidas para reducir la pobreza no obvian la necesidad de crecimiento" (Robert McNamara en World Bank, 1980, p. III).

${ }^{15}$ Sachs, de origen polaco, huyó de la persecución nazi en 1939, para refugiarse en 1941 en Brasil, donde residió hasta 1954, año de su graduación en Economía en la Facultad de Ciencias Económicas y Políticas de Río de Janeiro. Regresó a Polonia, cuyo gobierno le encomendó la presidencia de la delegación de la Conferencia de Bandung (1955). Tras su experiencia como em- 
que asesoraron la publicación del Founex Report on Development and Environment (1971), uno de los insumos para la Conferencia de Estocolmo, en la que al final se incluyeron los asuntos sociales (humanos) en la agenda medioambiental dentro del marco del desarrollo capitalista, con el crecimiento como solución a la pobreza (Jolly et al., 2009). El término ecodesarrollo fue utilizado públicamente por primera vez en 1973 por el director del Programa de Naciones Unidas para el Medio Ambiente (en adelante PNUMA), Maurice Strong. Sin embargo, el ecodesarrollo estaba presente en la postura de Commoner, crítica con respecto al Informe del Club de Roma, que implicaba "transformaciones económicas" en la dirección de una "reorganización radical de la sociedad humana para armonizarla con el imperativo ecológico", ya que "la fuerza propulsora principal de la tendencia contra la ecología que caracteriza al desarrollo de tecnologías productivas modernas radica en que la producción está motivada generalmente por el deseo de obtener beneficios a corto plazo" (Commoner, 1974, pp. 264, 279).

El ecodesarrollo, además de ser "la bandera de una lucha política contra las concepciones unilaterales del Club de Roma y sus adeptos", estaba articulado con la lucha del Tercer Mundo por la "creación de un nuevo orden mundial" (Leff, 1978, p. 304). Así, el ecodesarrollo surgió como una tercera vía entre los partidarios del desarrollismo capitalista del "crecimiento salvaje" y sus críticos partidarios del crecimiento cero, que, según Sachs, resultaron "víctimas de la absolutización del criterio ecológico hasta el punto de perder la visión antropocéntrica del mundo, que es la clave de todas las filosofías humanistas" (1980, p. 720).

De acuerdo con Sachs, el ecodesarrollo trata de "agregar una dimensión ambiental al concepto de desarrollo y a su planeamiento" sobre el supuesto de que "existe aún un margen de maniobra suficiente para diseñar estrategias de desarrollo viables, incluso desde el punto de vista ambiental" (Sachs, 1974a, pp. 57, 63). El ecodesarrollo tiene como puntos fundamentales: 1) la gestión racional de los recursos con planificación a largo plazo para su explotación sostenible encaminada a la satisfacción de las

\footnotetext{
bajador en la India (1957-1960), donde se doctoró en la Escuela de Economía de la Universidad de Delhi con una tesis sobre el capitalismo de Estado y el desarrollo en Brasil, conoció al joven maestro Amartya Sen (profesor en la Delhi School) y profundizó en el pensamiento desarrollista y limitarianista de Ghandi (por el que ya se había sentido atraído en la década de 1940). Regresó a su país para integrarse durante 1961-1968 en la Escuela Superior de Planificación y Estadística, donde colaboró con su presidente Michal Kalecki. Tras trabajar como consultor en la CEPAL (1968) y su paso por el PNUMA (1972), Sachs acabó dirigiendo a partir de 1985 el Centre de Recherches sur le Brésil Colonial et Contemporain de l'École des Hautes Études en Sciences Sociales (EHEss) de la Universidad de París, a donde Fernand Braudel lo invitó a raíz de los sucesos de 1968. Fue profesor visitante en el Instituto de Estudios Avanzados de la Universidad de São Paulo, y luego profesor honorario de la EHEss.
} 
necesidades básicas de nutrición, vivienda y energía, con la participación de la población local; 2) la reducción al mínimo de los impactos negativos, o bien, el aprovechamiento productivo de los afluentes y desechos para la conservación de los recursos naturales, y 3) el uso de tecnologías adecuadas para la industrialización de recursos renovables mediante la combinación de tecnologías de punta con otras intermedias, basadas en recursos naturales renovables y conocimientos tradicionales de la población local o "etnoecología" (Sachs, 1974a, pp. 65-68 y 1974b, p. 363).

Pero el concepto de ecodesarrollo es de más calado que su mera concreción operativa: enlaza con la noción de desarrollo como realización de las capacidades humanas ("como el hombre es el recurso más valioso, el ecodesarrollo debe contribuir ante todo a su realización"); ${ }^{16}$ anticipa la noción blanda del desarrollo sostenible, pero también la noción fuerte $;^{17}$ implica un desarrollo participativo que "presupone modalidades de organización social ["estructuras comunitarias" con "autoridad horizontal" y "participación efectiva de las poblaciones interesadas en la realización de las estrategias del ecodesarrollo"] y un sistema educativo nuevo que sirva para "sensibilizar a la gente respecto a la dimensión ambiental y a los aspectos ecológicos del desarrollo"; ${ }^{18}$ y es, por último, un desarrollo colectivo y centrado en sí mismo, que "confía en la capacidad de las sociedades humanas para identificar sus problemas y aportar soluciones originales", y por lo mismo "enaltece la autoconfianza (self-reliance)" (Sachs, 1974b, pp. 363-364). Como Sachs señaló años después, el ecodesarrollo se basa en "un criterio de racionalidad social diferente de la lógica del mercado" y en una "ética $[. .$.$] de la solidaridad sincrónica con la generación actual" [que$ es la que padece las "desigualdades sincrónicas" derivadas de la "racionalidad productivista"] y de la solidaridad diacrónica con las generaciones futuras" (Sachs, 1980, p. 720).

El ecodesarrollo intentó compatibilizar las demandas del movimiento ecologista internacional de los países desarrollados -que reclamaba el respeto a los ecosistemas necesario para mantener las condiciones de habita-

16 "El empleo, la seguridad, la calidad de las relaciones humanas, el respeto por la diversidad de culturas o, si se prefiere, el establecimiento de un sistema social que se considere satisfactorio, forman parte del concepto" (Sachs, 1974b, p. 364).

17 "la identificación, la valoración y el manejo de los recursos naturales se llevan a cabo con una perspectiva de solidaridad diacrónica con las generaciones futuras" (sostenibilidad blanda), y "el ecodesarrollo se apoya en la capacidad natural de la región para la fotosíntesis en todas sus formas", lo que "debería conducir a un perfil reducido de consumo de energía proveniente de fuentes comerciales, particularmente de hidrocarburos" (sostenibilidad dura) (Sachs, 1974b, p. 363).

${ }^{18}$ Ello pasa por "cambiar el sistema de valores con respecto a las actitudes frente a la naturaleza o, al contrario, preservar y reforzar, allí donde persista, la actitud hacia la naturaleza característica de ciertas culturas" (Sachs, 1974b, p. 364). 
bilidad de la tierra, de acuerdo con los planteamientos de la economía ecológica- y las demandas de desarrollo económico que tan perentoriamente reivindicaban los países del Tercer Mundo, organizados en torno a las propuestas del NOEI, amparadas por la Conferencia de Naciones Unidas para el Comercio y el Desarrollo (en adelante, UNCTAD) y con la fundamentación de las teorías estructuralista y dependentista del desarrollo, además de un fuerte activismo político internacional latinoamericano (Domínguez, 2016, pp. 61-65). Desde esa perspectiva, Furtado se encargó de recordar que el enfoque de los límites del crecimiento se basaba en el supuesto de que los países en desarrollo pudieran en algún momento adoptar el estilo de desarrollo de los Estados Unidos, lo que para este autor era simplemente un mito; ponía en cuestión el programa de convergencia de la Estrategia Internacional para la Segunda Década del Desarrollo (Furtado, 1974). ${ }^{19}$ Por eso, el ecodesarrollo no era contrario al crecimiento ni a la industrialización. Más bien confrontaba la propuesta del Founex Report de convertir los países del Tercer Mundo en "asilos de contaminación" y se adhería al objetivo de la Organización de Naciones Unidas para el Desarrollo Industrial marcado en la Cumbre de Lima de 1975 para que los países en desarrollo alcanzaran en el 2000 el 25\% de la producción industrial mundial (Sachs, 1977, p. 463).

Pero el ecodesarrollo representaba, además, una apertura interdisciplinaria de la economía a la antropología cultural y a la ecología, que invitaba a un cambio de enfoque, empezando por el diagnóstico. En vez de responsabilizar a la pobreza de la destrucción del medioambiente, como hacía el Informe Founex y los neomalthusianos del Informe del Club de Roma sobre los límites del crecimiento, la propuesta de Sachs afirma que "la destrucción ecológica causada por los pobres es consecuencia de la desigualdad de la distribución de la riqueza y de la tierra" (Sachs, 1977, p. 452). Por tanto, el concepto de límites externos (naturales) de la Conferencia de Estocolmo no es absoluto sino relativo, ya que depende de los arreglos institucionales y de la elección de las tecnologías disponibles que determinan la tasa de explotación de los recursos naturales, la cual se deriva del "consumo material conspicuo y de las necesidades artificialmente estimuladas" en los países desarrollados. Dicha tasa resulta mucho más importante que la

\footnotetext{
${ }^{19}$ Según Furtado, la implicación fundamental del Informe del Club de Roma sobre los límites del crecimiento es que "el estilo de vida producido por el capitalismo industrial debe preservarse para una minoría, pues todo intento de generalización del mismo al conjunto de la humanidad necesariamente provocará una crisis global del sistema. Esta conclusión resulta de la mayor importancia para los países del Tercer Mundo, pues pone en evidencia que la opción del desarrollo económico tal y como se ha definido y practicado en esos países -o sea, un camino de acceso a las formas de vida de los actuales países desarrollados- es simplemente un mito" (Furtado, 1974, p. 413).
} 
tasa de crecimiento de la población y del PIB de los países en desarrollo (Sachs, 1977, pp. 452-453). Según Sachs (1980, p. 720), había que "estudiar nuevas modalidades [de desarrollo], tanto en lo referente a los fines como en lo que concierne a los instrumentos, con el compromiso de valorizar los aportes culturales de las poblaciones que intervienen y de transformar en recursos útiles los elementos de su medio". Pero también había que estudiar el desarrollo en términos territoriales: "el desarrollo sólo se manifiesta en donde están y viven las personas, es decir, en las localidades" y por lo mismo "debe traducirse en el mejoramiento de las condiciones materiales e inmateriales de la vida de los habitantes", que es la condición para una "convivencia mejor y una mayor armonía con la naturaleza" (Sachs, 1980, pp. 720-721).

El ecodesarrollo, como un estilo de desarrollo más igualitario y menos dependiente, inspiró el simposio sobre Modelos de Utilización de Recursos, Medio Ambiente y Estrategias de Desarrollo, organizado por el gobierno de México y que tuvo lugar en Cocoyoc (Morelos) en octubre de 1974. La conferencia de científicos y economistas, celebrada bajo los auspicios del PNUMA y la UNCTAD, terminó con una declaración que acogió el presidente de México, Luis Echeverría, impulsor del NOEI y de la Carta de los Derechos y Deberes Económicos de los Estados, aprobados en septiembre y diciembre, respectivamente, en la Asamblea General de la ONU, lo que sitúa la Declaración de Cocoyoc en la línea de los esfuerzos para concretar ese proyecto (Domínguez, 2016).

La Declaración de Cocoyoc fue un texto con muchas aristas políticas, redactado en un lenguaje evocador del espectro de Marx, que arranca con la denuncia del orden mundial heredero de "casi cinco siglos de dominio colonial, durante los cuales el poder económico se concentró en forma predominante en un reducido grupo de países", que con $25 \%$ de la población mundial acaparaban "por lo menos las tres cuartas partes del ingreso mundial, de la inversión, los servicios y casi la totalidad de la investigación" (PNUMA/UNCTAD, 1974, p. 20). Esta situación, en "la que un centro explota a una inmensa periferia, lo mismo que al patrimonio común universal", reclamaba un NOEI que, defendiendo precios justos y sostenibles para las exportaciones de materias primas de los países en desarrollo, ${ }^{20}$ no violara los límites internos de las personas -el excesivo consumo de los ricos que impedía la satisfacción de las necesidades básicas para $40 \%$ de la población, integrada por los más pobres- ni los "límites externos" de la naturaleza, "los límites máximos de la explotación de nuestro planeta que

20 "Los bajos precios de las materias primas han venido a constituir un factor decisivo en el incremento de la contaminación y además han alentado el desperdicio y la economía del despilfarro entre los ricos" (PNUMA/UNCTAD, 1974, p. 21). 
pudieran causar efectos irreversibles y poner en peligro la existencia del hombre sobre la tierra" (PNUMA/UnCTAD, 1974, pp. 20, 22-23). Cocoyoc apeló a no enfocarse en el "desarrollo de los objetos sino del hombre" (PNUMA/UNCTAD, 1974, p. 21), para lo cual reclamó un desarrollo basado en la satisfacción de las necesidades básicas de alimentación, vestido, vivienda, salud y educación; la reducción de las desigualdades entre países y dentro de los países, porque la esperanza en el efecto trickle down es "ilusoria", ${ }^{21}$ y la ampliación de las libertades negativas (libertad de expresión y participación política), pero también de la libertad positiva del derecho a un trabajo, " en el que cada cual se sienta plenamente realizado en una ocupación" y que, como aclara el texto en alusión directa a Marx, "es el derecho a no verse alienado por causa de procesos de producción en los que se usa al ser humano simplemente como una herramienta" (PNUMA/ UNCTAD, 1974, p. 22).

En Cocoyoc se reafirma la idea de los estilos de desarrollo ("son diversos los caminos por los que puede alcanzarse el desarrollo") y la renuncia a la teoría de la convergencia, lo que significaba una revisión profunda de la finalidad del desarrollo que "no consiste en «nivelarse», sino en asegurar la calidad de vida para todos, con una base productiva compatible con las necesidades de las generaciones futuras" (PNUMA/UNCTAD, 1974, pp. 22, 24), en línea con el ecodesarrollo y las ideas de Furtado. La Declaración concluía con una llamada limitarianista para los países desarrollados (PNUMA/UNCTAD, 1974, p. 22) ${ }^{22}$ y de autoafirmación y autodeterminación colectiva para los países en desarrollo a partir de una "estrategia básica de desarrollo" tendente a que cada uno de ellos "tenga confianza en sus propias fuerzas, se apoye en sus propios recursos humanos y naturales y posea la capacidad autónoma necesaria para fijarse sus propias metas y tomar sus propias decisiones" (PNUMA/UNCTAD, 1974, p. 22). Así fue como el elemento "horizontal y totalizador" del concepto de ecodesarrollo (Sachs, 1980, p. 723), propagado inicialmente desde la publicística académica de América Latina para orientar los estilos de desarrollo de los países del Tercer Mundo, se convirtió en un arma de "lucha frontal e irreconciliable contra el capitalismo" (Leff, 1978, p. 308). Esa es la razón por la cual el concepto fue borrado enseguida del sistema de desarrollo de la ONU, y

\footnotetext{
21 “el proceso de crecimiento que beneficia únicamente a las minorías más prósperas y aumenta las disparidades entre países y dentro de ellos, no puede considerase desarrollo. Es explotación" (PNUMA/UNCTAD, 1974, p. 22).

${ }^{22}$ Este planteamiento filosófico, que supone poner límites a la riqueza (en vez de luchar contra la pobreza) para alcanzar la buena vida, queda reflejado en la siguiente afirmación: "debemos preocuparnos de volver a definir nuestras metas, así como estrategias nuevas de desarrollo y nuevos estilos de vida que incluyan pautas de consumo más modestas entre los ricos" (PNUMA/ CNUCYD, 1974, p. 22).
} 
sólo resistió en los márgenes del pensamiento periférico latinoamericano (Sejenovich, 2011).

\section{OTRO DESARROLLO O EL ECODESARROLLO DOMESTICADO}

En el momento álgido de la agenda del NOEI y de cara al séptimo periodo extraordinario de sesiones de la Asamblea General de la ONU en septiembre de 1975, la Fundación Dag Hammarksjöld (DH) empaquetó la agenda alternativa ecodesarrollista en su famoso informe Otro desarrollo en forma que resultara más digerible para la discusión dentro de la ONU. $\mathrm{El}$ informe parte de una posición ecléctica, ya que declara seguir la "ruta marcada" por el Founex Report y la Declaración de Cocoyoc y los aportes teóricos del Foro del Tercer Mundo, que, desde su creación en Chile en 1973, agrupaba a los elementos liberales y progresistas para trabajar por la creación de un orden mundial más justo (Fundación DH, 1975, p. 1). El infome DH contó entre sus tres consejeros principales con Ignacy Sachs, tuvo la colaboración de Celso Furtado en las reuniones preparatorias (Fundación DH, 1975, pp. 131-132) y su "utopismo por transferencia" (Wolfe, 1976, p. 147) fue, sin duda, producto de la financiación del Ministerio Holandés de Cooperación para el Desarrollo, dirigido por el socialista Jan Pronk, y de la Agencia Sueca de Desarrollo Internacional, también con dirección socialdemócrata y con la referencia teórica de Gunnar Myrdal, inspirador del enfoque unificado de desarrollo de la Estrategia Internacional para la Segunda Década. Dividido en tres bloques (hacia otro desarrollo, hacia un nuevo orden internacional y hacia un nuevo sistema de desarrollo y cooperación internacional de la ONU), de los que nos centraremos en el primero, el informe inicia con el diagnóstico de la "crisis del desarrollo". Dicha crisis ocurre en el interior de los países por tres factores: pobreza de las masas del Tercer Mundo que no tienen satisfechas sus necesidades básicas; "alienación, sea en la miseria o en la abundancia, de las masas desprovistas de los medios necesarios para comprender y gobernar su ambiente político y social", y "sentimientos de frustración que están trastornando las sociedades industriales". Pero la crisis del desarrollo es también una crisis en las relaciones internacionales por la desigualdad "entre unos pocos países dominantes y la mayoría de los pueblos dominados", que se refleja en la incapacidad de las instituciones para adaptarse a los rápidos cambios en la economía internacional asociados al final de la guerra de Vietnam y al aumento del precio del petróleo (Fundación DH, 1975, pp. 5-6).

En ese contexto, "es posible otro desarrollo", que debe basarse en el "desarrollo de cada hombre y mujer y de toda la persona humana, y no sólo [en el] crecimiento de cosas, que son meramente medios". Un de- 
sarrollo que debe ir dirigido a la satisfacción de las necesidades básicas de los pobres, pero también a "asegurar la humanización del hombre al favorecer sus necesidades de expresión, creación, convivencia y decisión sobre su propio destino". Un desarrollo multidimensional y "endógeno" y de "autodependencia colectiva" (Fundación DH, 1975, p. 73), ${ }^{23}$ que "brota de las entrañas de cada sociedad, al definir soberanamente la visión de su futuro, en cooperación con sociedades que comparten sus problemas y aspiraciones" y supone "la soberanía económica nacional sobre los recursos y la producción". Y un desarrollo "en armonía con el medio ambiente" que, reconociendo la existencia de "límites ecológicos a la acción de los hombres" o "límites externos", ${ }^{24}$ sea capaz de superar los límites internos, que son "sociales y políticos", por medio de transformaciones estructurales tales como reformas agrarias y urbanas, de los circuitos comerciales y financieros, la redistribución de la riqueza y los medios de producción y la descentralización para la democratización del poder político y económico (Fundación DH, 1975, pp. 7, 13-16 y 28).

El informe Otro desarrollo representó el punto culminante de las "utopías concretas ideadas por comités" de expertos, es decir "intelectuales y reformadores que se encuentran, formando diferentes combinaciones, en un foro tras otro" (Wolfe, 1979, pp. 9-10). Y aunque su director diría cuatro años después de la publicación del informe que "otro desarrollo significa liberación" (Nerfin, 1979, p. 11), se eludieron los aspectos clave de si el programa propuesto debía "producirse por la conversión de los poderosos o por su derrocamiento" y de si el crecimiento del ingreso per cápita mantenía o no su validez (Wolfe, 1979, p. 9). Basta con analizar las opiniones de uno de sus financiadores clave, el socialista holandés Jan Pronk, antiguo asistente de Jan Tinbergen, ${ }^{25}$ para entender esas ambigüedades, pero también las potencialidades del concepto. Pronk plantea avanzar en el NOEI a través de la Internacional Socialista, una tercera vía transversal entre los intereses del Norte y los del Sur, y defiende un estilo de desarrollo nacional e internacional (para los países en desarrollo), que debería implicar "crecimiento, autodeterminación y justicia social", un "desarrollo humano

${ }^{23}$ Dicha autodependencia (self-reliance) tiene que asumir la forma de "la 'sindicalización' de los países del Tercer Mundo tendente a aumentar el poder de negociación de los países en su participación en la economía internacional, mediante el empleo de su capacidad latente, subutilizada o no utilizada, de emprender una acción conjunta en sus relaciones con los países industrializados".

${ }^{24}$ Estos límites "son el punto a partir del cual un recurso no renovable se agota o un recurso renovable, o un ecosistema, pierden su capacidad de regenerarse o de cumplir sus funciones principales en los procesos biofísicos" (Fundación DH, 1975, p. 36).

${ }^{25}$ Pronk financió el llamado Informe RIO (Reshaping International Order) de 1976, que Tinbergen coordinó para el Club de Roma, y en el que participó, entre otros, Ignacy Sachs. El Informe RIO abogó por convertir la Carta de Derechos y Deberes de los Estados en un tratado internacional con efectos legalmente obligatorios para sacar adelante el programa del NOEI. 
[que] significa un desarrollo orientado hacia los pobres" y que cuente con su participación activa (Pronk, 1978, pp. 77, 81 y 87-88). En el desglose de estos puntos, Pronk se expresa en el lenguaje de las armonías que anticipa las preocupaciones posdesarrollistas del Buen Vivir, pero también de los derechos ciudadanos característico del futuro discurso neodesarrollista, de raíz socialista, de ese nuevo estilo de desarrollo. ${ }^{26}$

El debate de los estilos de desarrollo y las propuestas de desarrollo alternativo propias del utopismo de las "revoluciones sin sujeto" (Cardoso, 1980, pp. 856 y 860) sirvieron para explicitar tres posturas definidas por Aníbal Pinto, ${ }^{27}$ que acabaron convergiendo, en la década siguiente, en torno al desarrollo a escala humana, pero ya en otro contexto -el contexto sobrecogedor de la crisis de la deuda-y por muy distintos motivos.

\section{TERCERA DÉCADA: ESTILOS DE DESARROLLO ALTERNATIVO Y DESARROLLO A ESCALA HUMANA}

Pese al resultado decepcionante del crecimiento de los países en desarrollo durante la Segunda Década, la siguiente se inició con la nueva Estrategia de Desarrollo Internacional para la Tercera Década del Desarrollo de la ONU aprobada en diciembre de $1980^{28}$ de marcado carácter voluntarista. Entre 1971 y 1980, el crecimiento acumulativo del PIB (5.1\%) y del PIB per cápita $(2.6 \%)$ en los países en desarrollo había quedado por debajo de los objetivos de 6 y 3.5\%, respectivamente (Jolly et al., 2009). En este contexto, con la sombra de la crisis de la deuda que se alargaba por momentos, la nueva Estrategia ganó en retórica lo que perdió en anclaje en la realidad, un marco internacional que permitiera "reducir significativamente las actuales disparidades entre países desarrollados y en desarrollo, así como la pronta erradicación de la pobreza y la dependencia" (con referencia incluida a la industrialización y la collective self-reliance). Este giro retórico expresa la frágil solución negociada entre la agenda de necesidades básicas, dominada a esas alturas por el Banco Mundial, y la agenda del NOEI, laminada en la segunda mitad de los años setenta por las tácticas divisionistas

\footnotetext{
26 "un proceso de desarrollo basado en la armonía, tanto entre la gente misma como entre la gente y su ambiente natural [...] un proceso de desarrollo basado en la armonía entre el presente y el futuro [...] un proceso de desarrollo basado en la preservación de los derechos humanos económica, social, cultural y políticamente [...] un proceso de desarrollo basado en la solidaridad, que tenga lugar en la libertad y que conduzca a la igualdad" (Pronk, 1978, p. 82).

27 "de los que están saciados y hastiados con la 'sociedad opulenta'; de los que se hallan a medio camino y critican la supuesta deseabilidad de esa meta; y, en último término, de quienes no quieren y tiene poca o ninguna posibilidad de reproducir el modelo rechazado" (Pinto, 1976, p. 98).

${ }^{28}$ Véase el texto en http://www.un-documents.net/a35r56.htm.
} 
de los países centrales y la incubación de la crisis de la deuda que acabaría arrumbando la unidad del Tercer Mundo (Domínguez, 2016). La Estrategia contiene metas específicas no sólo para los agregados económicos, ${ }^{29}$ sino, y por primera vez, de "reducción y eliminación de la pobreza" y el hambre, con el compromiso de alcanzar en 2000 el pleno empleo, la escolarización primaria universal, el aumento de la esperanza de vida en los países en desarrollo hasta 60 años, y, en los países más pobres, tasas de mortalidad general no superiores a $120 \%$ e infantil no superiores a 50\%0 (Jolly et al., 2009; Koehler, 2015).

\section{Desarrollo humano y estilos de desarrollo cepalinos}

El Banco Mundial aceptó entonces la terminología del "desarrollo humano" de la ONU, la vació de contenido y la redujo a desarrollo individual, para luego propiciar los programas de ajuste estructural que hicieron de la Tercera Década la década perdida del desarrollo. Este movimiento de limpieza ideológica, que tuvo su aperitivo en un discurso de Henry Kissinger $(1976$, p. 672) ante la IV UNCTAD para combatir el NOEI, y su noción de desarrollo colectivo $(1976)^{30}$ fue la respuesta a la Evaluación de Quito de la Estrategia de Desarrollo Internacional para la Segunda Década del Desarrollo realizada por la CEPAL en 1973, en la que se reclamaba, como condición para la realización del desarrollo humano, la eliminación de las "estructuras tradicionales" (a modo de "obstáculos"), mediante "cambios estructurales" o "cambios institucionales" referidos a los derechos de propiedad (el control soberano de los recursos naturales, la reforma agraria, y reformas en la propiedad de los medios de producción hacia esquemas públicos, para lograr un "desarrollo económico autosostenido independiente") (ECLA, 1973, pp. 3-4). El entendimiento del desarrollo humano por parte del entorno de la CEPAL en este documento iba mucho más allá de la inversión en recursos humanos (que es la que realizó el Banco Mundial en 1980), sino que contiene un programa de liberación de resonancias socialistas: "los objetivos de desarrollo en América Latina deben ser la creación de una nueva sociedad y un nuevo tipo de hombre. La participación social

${ }^{29}$ Con crecimientos anuales para el decenio de 7\% del PIB, 4.5\% del PIB per cápita, 7.5 y $8 \%$ de las importaciones y exportaciones de bienes y servicios, $4 \%$ del VAB del sector agrario y $9 \%$ del $\mathrm{VAB}$ del sector industrial, con una tasa de formación bruta de capital de entre 24 y 28 por ciento.

30 "El desarrollo es una empresa humana. Son los talentos y esfuerzos de los individuos los que convierten en realidad el desarrollo, y son ellos quienes resultan sus últimos beneficiarios [...] Por tanto, el desarrollo debe mirar más allá de la supervivencia a fin de proporcionar las oportunidades para la educación, mayor libertad personal, dignidad individual, y respeto por uno mismo" (énfasis añadido). 
en todas las formas del proceso de desarrollo debe ser aumentada para lograr una sociedad más justa." ${ }^{31}$

Con estos antecedentes, la CEPAL presentó en 1979 su aporte a la Estrategia de Desarrollo Internacional para la Tercera Década del Desarrollo todavía con la esperanza puesta en el NOEI, de manera que la propuesta debía "contribuir a la promoción del objetivo de la autosuficiencia nacional y colectiva de los países en desarrollo" (CEPAL, 1981). La propuesta se estructuró a partir de una clasificación de metas y objetivos cuantitativos y cualitativos organizados en torno a seis áreas de las que nos interesan tres: "1) desarrollo económico; 2) desarrollo social y humano, y 3) autosuficiencia y movilización de recursos nacionales" (CEPAL, 1981, pp. 468-469). Para el desarrollo económico se estimaron metas y objetivos cuantitativos que, retrospectivamente con la década perdida, resultan de un voluntarismo heroico $(7.5 \%$ de crecimiento del PIB y $8 \%$ de crecimiento del VAB industrial, coeficiente de ahorro bruto de $23 \%$, y $8 \%$ de crecimiento del comercio de importación y exportación). Para el desarrollo social y humano, se planteó la necesidad de contar con indicadores para las finalidades esenciales del crecimiento económico, como el "acrecentamiento del bienestar social y su plena participación en el proceso de desarrollo", el "mejoramiento de la distribución del ingreso y la riqueza", así como otros objetivos específicos sobre los siguientes temas: "erradicación de las situaciones de pobreza extrema e indigencia"; "empleo, nutrición, educación, salud y vivienda"; "bienestar de la niñez, la participación de la juventud y la integración de la mujer", y "la preservación del medio ambiente". Para la autosuficiencia y movilización de los recursos nacionales, se formularon nada menos que cuatro objetivos generales de carácter cualitativo: "la identidad cultural y el desenvolvimiento de formas y estilos propios de vida"; "la plena movilización de los recursos humanos y materiales como la base principal de sustentación del crecimiento propio"; "la aceleración de la inversión y formación de infraestructura", y "la elevación de la productividad, la contención del consumismo y el acrecentamiento del ahorro para impulsar la acumulación" (CEPAL, 1981, pp. 470-476).

Un año después se publicaron los resultados del proyecto conjunto entre la CEPAL y el PNUMA, Estilos de desarrollo y medio ambiente en América Latina, que se había llevado a cabo desde mediados de 1978 hasta mediados de 1980. En el trabajo introductorio, Osvaldo Sunkel presentó un balance de los "estilos de desarrollo alternativos" que se habían llevado a cabo en la

${ }^{31}$ De hecho, el representante de Estados Unidos propuso enmendar o sustituir las alusiones referidas a "cambios radicales": la soberanía sobre los recursos naturales matizada con la adecuada compensación "en caso de nacionalización... de acuerdo al derecho internacional", y la alusión a las "estructuras tradicionales" suprimida porque "en muchos casos las estructuras tradicionales existentes a menudo realizan una valiosa contribución al desarrollo” (ECLA, 1973, p. 7). 
región en las dos décadas previas, señalando como una de las principales fallas que "no prestaron consideración adecuada a la dimensión ambiental en el análisis integral del proceso de desarrollo" (Sunkel, 1980, p. 10). Si en la década de 1970 se había tratado de integrar el desarrollo económico y el social, buscando el isomorfismo con el "estilo internacional ascendente" (el de Estados Unidos), ahora había que añadir el componente ambiental a fin de eliminar en lo posible los rasgos negativos de ese "estilo transnacional" (las desigualdades entre clases y grupos, el gasto improductivo del excedente en armamentos y el consumo desorbitado de energía y recursos naturales) (Sunkel, 1980, pp. 10-11, 27).

La urbanización característica del modelo de desarrollo de los países capitalistas desarrollados generaba la falsa ilusión de que los seres humanos cada vez dependen menos de la naturaleza ("artificialización"), al perderse "uno de los procesos formativos culturales más importantes", que, para Sunkel (1980, pp. 11, 16), es "la adquisición de una sabiduría ecológica empírica en relación con las formas permisibles y tolerables de explotación de la naturaleza circundante, de cuya reproducción depende la supervivencia de la población”. Sunkel llama la atención sobre los modos de apropiación social de los elementos de la biosfera (tierra, agua y recursos naturales) por ser uno de los "determinantes decisivos de la desigualdad social y de la estructura de poder": dicha apropiación no es únicamente un fenómeno rural sino también urbano, ${ }^{32}$ y además de interno también internacional y explica la división centro-periferia, sus especializaciones productivas respectivas y, en definitiva, los diferentes estilos de desarrollo (Sunkel, 1980). Pero el concepto de estilo de desarrollo puede aplicarse no sólo a lo que es, sino a lo que debe ser (Sunkel, 1980), de tal manera que el autor se aplica a formular un estilo alternativo.

Sunkel cuestiona la sostenibilidad del estilo de desarrollo ascendente o transnacional de origen importado: "es legítimo preguntarse si no es acaso muy peligroso financiar un estilo de vida y de desarrollo que no se sostiene a sí mismo mediante la exportación de recursos naturales más o menos limitados y sustituibles, sujetos además a los vaivenes del mercado internacional" (Sunkel, 1980, p. 51). Y sus preguntas de entonces resuenan hoy más que nunca en los debates sobre el neoextractivismo progresista del Buen Vivir: “¿puede ese patrón de desarrollo generar con el tiempo una

32 "El excedente generado por la explotación de la naturaleza permite la construcción de un medio ambiente artificial extremadamente favorable y grato para los sectores de ingresos medios y altos, y bastante precario para los sectores populares. Ello da lugar a una situación en que la preocupación ambiental de los sectores pudientes es por la calidad de la vida [...] mientras que las consideraciones ambientales que preocupan a los pobres -la contaminación del agua, la distancia de los lugares de trabajo, la precariedad y hacinamiento de las viviendas, etcétera- atentan contra su vida misma" (Sunkel, 1980, p. 59). 
diversificación y expansión del potencial de exportaciones suficientemente amplio y dinámico como para financiar buena parte de sus propias necesidades crecientes de financiamiento externo?" (Sunkel, 1980, p. 51).

Entonces (como ahora) el problema era "satisfacer las necesidades más apremiantes de la mayoría de la población", objetivo que, a la vista de los magros resultados, precisaba un cambio en el estilo de desarrollo a favor de la expansión de "la "producción de bienes básicos en los sectores de la alimentación, el vestuario, el calzado, y de los servicios básicos de seguridad social, vivienda, salud y educación" (Sunkel, 1980, p. 52). Por tanto, el cambio de estilo no suponía "dejar en suspenso el crecimiento económico", sino reorientarlo para que generara los recursos necesarios a fin de satisfacer las necesidades básicas. Este estilo alternativo debía compatibilizar "la satisfacción de las necesidades fundamentales de la mayoría de la población" con "la preservación y valorización de la base de los recursos y del medio ambiente de la sociedad"; debía reducir la dependencia con respecto a las fuentes de energía fósiles, desarrollar tecnologías intensivas en mano de obra y ajustarlas a la base de recursos naturales, "administrar los recursos naturales con conocimientos tecnológicos apoyados en bases ecológicas", reorganizar la actividad descentralizándola de las concentraciones urbanas y reducir los "excesos del consumismo" (Sunkel, 1980, p. 53). Un programa de tal calado, que "pone en duda una serie de creencias derivadas de la ideología del crecimiento económico" (como fenómeno exponencial e ilimitado, basado en la explotación y la artificialización de la naturaleza y la acumulación de bienes materiales de consumo), requería una amplia participación de la población y un esfuerzo masivo de reeducación de la población para que "internalice la dimensión ambiental y los aspectos ecológicos del desarrollo" (Sunkel, 1980, p. 61-63).

\section{El tercer límite del desarrollo: desarrollo a escala humana}

Si la Primera Década del Desarrollo estuvo dominada por la preocupación de los aspectos sociales (o límites internos) en el desarrollo y la Segunda por los aspectos ecológicos (o límites externos), en la Tercera irrumpieron las cuestiones subjetivas. Fue al pionero español del desarrollo, José Luis Sampedro (Domínguez, 2013), a quien cabe atribuir la introducción de este tercer límite, el psicológico, que hace referencia al "deterioro del sentido de la identidad reflejado diariamente en tantas manifestaciones de desconcierto y búsqueda de asideros" y que es producto de darle más importancia al "tener" que al "ser" (Sampedro, 1983, p. 1666) o, como dirá más adelante, "hecho a costa de la vida interior del hombre [...] dejándole un vacío interno provocador de ansiedades y aberraciones" (Sampedro, 
1987, p. 39). Sampedro (1983, p. 1663) apunta la contradicción entre "la conciencia de que el planeta es el primer bien escaso" y la ignorancia de este hecho por "una teoría convencional que, sin embargo, hac[e] de la escasez su categoría identificadora como ciencia" (Sampedro, 1980, p. 362). Pero va más allá de lo que él considera límites físicos y políticos: para Sampedro la salida de la "crisis del desarrollo", una tecnocracia que se hace "a costa de la naturaleza, de otras culturas o de la vida interior" y que "conduce a una progresiva degradación humana" (Sampedro, 1983, pp. 1667-1668), consiste en un cambio de valores para la "humanización del desarrollo" de la que ya habló en 1982 (Sampedro, 2009, p. 347). Y para transformar ese modelo insostenible era necesaria una "descolonización mental" o "revolución cultural" que pasaba por un nuevo enfoque metaeconómico, "un campo que está más allá de la economía" como tercer nivel de realidad axiológico, y que Sampedro identifica con el paradigma del "ecodesarrollo" (Sampedro, 1983, pp. 1655, 1660, 1663 y 1667).

En efecto, a inicios de la década de 1980, para Sampedro la "salvación" -frente al "desarrollo como cáncer (Sampedro, 2009, p. 335) o frente al "desarrollismo, con su falso ideal del crecimiento perpetuo" como "dimensión patológica de la cultura occidental" (Sampedro, 2009, p. 352) - habría que buscarla en "la adopción de otra vía de desarrollo" que rompiera con "la atrofia de fines frente a la hipertrofia de medios": una economía preocupada por la pobreza desde un "desarrollo humanizado" que debería corregir "el desequilibrio fundamental de la industrialización: la preferencia por las cosas en lugar de por los hombres" (Sampedro, 2009, pp. 341-345). Superar la crisis sistémica o crisis del desarrollo implicaba superar el "desarrollo explotado a costa de la naturaleza, de otras culturas o de la vida interior" (Sampedro, 1983, p. 1667). Este cuestionamiento del paradigma utilitarista en el que se apoyaba toda la economía del desarrollo (no sólo la economía del crecimiento, sino también las teorías del subdesarrollo de raíz estructuralista-dependentista) con argumentos muy similares y anticipatorios de los de Amartya Sen: "la libertad -había afirmado Sampedro en 1978- solamente se conquista, porque no es un bien para consumir, sino para ejercer. Se produce ejerciéndola, que es justamente su goce" (Sampedro, 2009, p. 92).

En 1980 Sampedro reivindicó "el desarrollo ecológico o ecodesarrollo" (Sampedro, 1980, p. 367) y poco después, tras denunciar "la desviación del desarrollo hacia fines puramente materiales y cuantitativos", reclamó "la necesidad de un nuevo desarrollo, humano y ecológico", basado en la solidaridad, que recuerda las tres armonías del Buen Vivir: "¿por qué no imaginar que la nueva cultura del siglo XXI se funde sobre la 'solidaridad', como aproximación al menos a la fraternidad? Solidaridad con nuestros conciudadanos; solidaridad entre los pueblos; solidaridad con el 
medio ambiente, porque es también, en cierto sentido, nosotros mismos; solidaridad -más bien soldadura- entre nuestra vida exterior y la interior" (Sampedro, 2009, p. 254).

La propuesta del tercer límite psicológico de Sampedro formaba parte de un esquema de pensamiento original iberoamericano que fue coincidente con, e influyó profundamente en, el planteamiento de la economía descalza del chileno de origen alemán Manfred Max-Neef, quien alude así al método de la observación participante que lleva al economista a "vivir y compartir la realidad invisible" (Max-Neef, 1982, p. 41)..$^{33}$ La preocupación de Max-Neef, como la de Sampedro, era la deshumanización de la economía. Ambos consideran que en los inicios de la década de 1980 hay una "crisis total" cuya causa final es el intento humano de "someter a la naturaleza" mediante el "estilo vandálico" de desarrollo predominante medido por la variación del PNB, esto es, por las "actividades que se generan a través del mercado, sin considerar si dichas actividades son productivas, improductivas o destructivas" (Max-Neef, 1982, pp. 40, 42-43 y 51). De ahí su propuesta para elaborar un "nuevo cuantificador" denominado "econson" o "drenaje razonable de los recursos que una persona necesita para lograr una calidad de vida aceptable", considerando como tales recursos "los requerimientos de energía, nutrición, vestuario y vivienda" (Max-Neef, 1982, p. 61). Dicha medida está asociada al desarrollo "deseable" ("el desarrollo en el cual creemos y que buscamos") y que epistemológicamente es caracterizado como un "humanismo ecológico integral", pero que el Nobel alternativo no remite al pensamiento de Marx sino al "eco-anarquismo humanista" (Max-Neef, 1982, pp. 48, 62-63, 72). Este punto, a nuestro juicio, es la línea divisoria crítica entre toda la tradición anterior de los estilos del desarrollo, que es de raíz socialista, y lo que MaxNeef acabó denominando después desarrollo a escala humana, que, con sus propuestas de interdependencia, identidad e integración entre seres humanos y naturaleza, y de desconcentración del poder y a favor de la escala reducida de la producción, conectó con los nuevos planteamientos posdesarrollistas de las corrientes indigenista y ecologista del Buen Vivir:

\footnotetext{
${ }^{33}$ El término procede de la llamada a favor de un nuevo tipo de expertos, "expertos descalzos", que necesitarán "subordinar sus propios valores, aun sus conocimientos, a los de la comunidad que está tratando de servir" (Tinbergen, 1977, pp. 170-171). Max-Neef fue muy influido por los movimientos comunitaristas (grassroots) seguidores de las doctrinas de Ghandi, pero a través del filtro de Fritz Schumacher -otro gran concentrador intelectual como Seers-, y su reivindicación de la buena vida de tradición keynesiana a través del filtro de Marx y el propio Ghandi (Chick, 2013). Esta postura fue producto de su crisis personal como economista del desarrollo después de una trayectoria en la que Max-Neef, que empezó trabajando para Shell, se orientó hacia la academia (con una tesis sobre estructura social y desarrollo económico con la que se doctoró en la Universidad de Chile) y de ahí a la consultoría internacional con la FAO y la OIT, para cuya Misión Andina trabajó en Ecuador a principios de la década de 1970.
} 
"Ya no creo en 'soluciones nacionales' o 'estilos nacionales'... Por ende creo, como economista descalzo, en la acción local y en pequeñas dimensiones" (Max-Neef, 1982, p. 136).

Max-Neef sigue la línea del enfoque original de necesidades básicas de Seers y la Fundación Bariloche (en la que trabajó durante parte de su exilio tras el golpe de Estado de Pinochet); pero, como Amartya Sen, trasciende la aproximación materialista del fetichismo de la mercancía (Stewart, 2006) y lo hace marcado ya por el contexto de desencanto con el socialismo real, la pérdida de eficacia de las fórmulas keynesianas y el descrédito de las medidas neoliberales (Espinoza, 1988). Tras reconocer que las necesidades son finitas, Max-Neef introduce la distinción fundamental entre necesidades y satisfactores, que data de un primer trabajo de 1978 para la Fundación Bariloche (Espinoza, 1988). Las necesidades no están jerarquizadas sino interrelacionadas en una matriz, sobre la base de las categorías existenciales de "Ser, Tener, Hacer, Estar", y categorías axiológicas de "Permanencia (Subsistencia), Protección, Afectos, Entendimiento, Participación, Ocio, Creación, Identidad y Libertad". Por lo mismo, las necesidades humanas fundamentales son "las mismas en todas las culturas y en todos los periodos históricos" y lo que varía son los satisfactores, definidos como "la manera o los medios utilizados para la satisfacción de las necesidades" (Max-Neef, 1982, pp. 237-238; Max-Neef, Elizalde y Hopenhayn, 1986, pp. 25-27). Así, cada sistema social y político "adopta diferentes estilos para la satisfacción de las mismas necesidades humanas fundamentales", de manera que no tiene sentido hablar de pobreza: sólo hay pobrezas o distintas dimensiones existenciales o axiológicas de pobreza (Max-Neef, 1982, pp. 239-240; Max-Neef et al., 1986, pp. 27-29, 41-42).

Sobre esas premisas epistemológicas, el trabajo de Max-Neef y sus colaboradores en la Fundación Dag Hammarskjöld de 1986 es un intento de adaptar el informe Otro desarrollo de 1975 al contexto latinoamericano "a la luz de los cambios de escenario ocurridos durante el último decenio" (Max Neef et al., 1986, p. 5). Se trata de recuperar, frente a la "crisis de la utopía", el pensamiento de lo "deseable-posible" después de lo que se describe como fracaso del desarrollismo cepalino y del neoliberalismo monetarista, que los autores contemplan en sus rasgos comunes de mecanicismo y sus resultados económicos concentradores (Max-Neef et al., 1986, pp. 10-13, 72). Frente a esa crisis se propone un "Desarrollo a Escala Humana" (DEH), basado en la satisfacción de las necesidades humanas fundamentales, en la generación de niveles crecientes de autodependencia y en las cuatro articulaciones orgánicas (seres humanos y naturaleza, lo local y lo global, individuo y sociedad, sociedad civil y Estado), con la premisa de dar protagonismo real a las personas, privilegiando "tanto la diversidad como la autonomía de espacios en que el protagonismo sea realmente 
posible. Lograr la transformación de la persona-objeto en persona-sujeto del desarrollo" (Max-Neef et al., 1986, pp. 14-15). Detrás de esta retórica humanista ("al fetichismo de las cifras debe oponerse el desarrollo de las personas"), el DEH tiene, sin embargo, dos puntos de aggiornamento a los años de plomo del neoliberalismo, que supone un claro retroceso respecto a la agenda socialista del otro desarrollo en sus vertientes de planificación e internacionalismo: un paso adelante humanista, subjetivista y post-materialista, pero dos pasos atrás en la vertiente socialista, igualitaria e internacionalista, por su concepción subalterna del papel del Estado (Max-Neef el al., 1986, pp. 62, 77) ${ }^{34}$ y su abandono de la reivindicación del NOEI, tras su aplastamiento en la Conferencia sobre Cooperación Económica Internacional de Cancún de 1981 (Domínguez, 2016), a favor de un fraudulento localismo metodológico. ${ }^{35}$

Finalmente, el DEH añade a la economía descalza y su matriz de necesidades y satisfactores los tres elementos relacionales (armonía con uno mismo, con la comunidad y con la naturaleza) que serán definitorios del Buen Vivir como síntesis de los estilos de desarrollo alternativo (y alternativa al desarrollo) del siglo XXI. Así, cada necesidad puede satisfacerse " $a$ ) en relación con uno mismo (Eigenwelt); $b$ ) en relación con el grupo social (Mitwelt), y $c$ ) en relación con el medio ambiente (Umwelt)" (Max-Neef et al., 1986, p. 27). El DEH anuncia una promesa de epistemología de la praxis verdaderamente transformadora: "acceder al ser humano a través de las necesidades permite tender el puente entre una antropología filosófica y una opción política y de políticas" con mención explícita a Marx (Max-Neef et al., 1986, p. 34). Pero a continuación cierra el paso a la política pública: dado que las necesidades se conciben como "carencia y potencia, resulta impropio hablar de necesidades que se 'satisfacen' o que se 'colman'”, por lo que debería hablarse de "vivir y realizar las necesidades, y vivirlas y realizarlas de manera continua y renovada", es decir, se trata de dar prioridad a los "satisfactores endógenos y sinérgicos" que surgen de la sociedad civil (de abajo hacia arriba), y por esta nueva magia del "desarrollo endógeno"

${ }^{34} \mathrm{El}$ DEH hace de la necesidad (la incapacidad del Estado jibarizado por el fundamentalismo de mercado que vivió Chile desde la dictadura de Pinochet) virtud y propone un Estado que, en vez de proporcionar los "satisfactores exógenos" (programas públicos de nutrición, salud, y vivienda), se convierta en "estimulador y potenciador de procesos emanados desde abajo hacia arriba", basados en una "autodependencia" consistente en la "regeneración o revitalización a través de los esfuerzos, capacidades y recursos de cada uno" (cursivas nuestras), complementada con capital social (recursos que van más allá de los económicos, como conciencia social, cultura organizativa y capacidad de gestión, creatividad popular, energía solidaria y capacidad de ayuda mutua) y cooperación internacional, lo que forma el clásico paquete neoliberal de desarrollo humano, sin cambio estructural, al que se renuncia de partida.

35 “ningún Nuevo Orden Económico Internacional podrá ser significativo si no está sustentado en la reformulación estructural de una densa red de Nuevos Órdenes Económicos Locales” (Max-Neef, Elizalde y Hopenhayn, 1986, p. 23). 
sui generis "conciliar el crecimiento económico, la solidaridad social y el crecimiento de las personas y de toda la persona" (Max-Neef et al., 1986, pp. 50-51 y 64). ${ }^{36}$ Ahora bien, mientras en la economía descalza Max-Neef (1982, p. 52) habla de un "humanismo ecológico capaz de sustituir, o, por lo menos de corregir, el antropocentrismo que prevalece entre nosotros", en el Informe DEH ya denuncia la "cosmología antropocéntrica que sitúa al ser humano por encima de la naturaleza" y que es propia de los "estilos tradicionales de desarrollo" y su "visión economicista", portadora de la creencia de que la "depredación indiscriminada de un recurso natural hace aumentar el PGB [producto interior bruto]" (Max-Neef et al., 1986, p. 57). El DEH allana, así, el camino para el posdesarrollo de la corriente ecologista e indigenista del Buen Vivir.

\section{CONSIDERACIONES FINALES: TOMANDO EN SERIO EL OTRO DESARROLLO}

El objetivo de este artículo era probar la conexión directa e indirecta del otro desarrollo con las variantes de estilos de desarrollo que han tomado fuerza en la región desde los inicios del siglo XxI, y que se han concretado en el Buen Vivir. Efectivamente, el Buen Vivir, como lema de la política pública de la Revolución Ciudadana de Ecuador (2007-2016), expresa un estilo de desarrollo, de acuerdo con la definición de Graciarena (1976, p. 186) comentada en la introducción.

Si se confronta la literatura más reciente sobre el Buen Vivir como política pública (véase Domínguez, Caria y León, 2017) con las características que se pueden extraer del análisis precedente y la vieja evaluación sobre las publicaciones del otro desarrollo que hace más de 30 años hizo José Ángel Moreno (1985, pp. 331-346), parece confirmarse la hipótesis de la conexión latente entre el otro desarrollo y la variante actual del estilo de desarrollo que se concretó en los Planes Nacionales para el Buen Vivir (subtitulados Planes Nacionales de Desarrollo). Este último autor establece el decálogo o común denominador de las propuestas del otro desarrollo: a) "hincapié en la satisfacción de las necesidades básicas", que implica lucha contra la pobreza y la desigualdad; b) "necesidad de intensificar el "esfuerzo interno", basado en la movilización de los recursos endógenos; c) "movilización popular y participación social", a fin de conseguir "un

${ }^{36}$ Furtado (1984, pp. 185-191) describió tres vías para la consecución del desarrollo endógeno, que quedan completamente ausentes (o son directamente rechazadas) en el análisis del DHE: la colectivización de los medios de producción; la satisfacción de las necesidades básicas de la colectividad, que "requiere modificar el perfil de la distribución del ingreso", y el aumento del grado de autonomía externa, que "consisten en asumir una posición ofensiva en los mercados internacionales". 
amplio consenso sobre las metas de desarrollo perseguidas y la forma de conseguirlas, para lo cual será necesario promover la organización de los sectores que puedan verse favorecidos por esas prácticas", mediante "una redistribución considerablemente más equitativa del poder social"; $d$ ) "rearme cultural" mediante una política educativa y cultural que reafirme "la cultura y los saberes propios"; e) "reorientación hacia las producciones básicas", con "atención prioritaria al crecimiento de la producción agraria e industrial orientada al mercado interno"; $f$ ) "máxima creación de empleo", considerado no sólo en términos de aumento de la actividad sino como "elemento básico para el desarrollo de la persona"; g) "atención al sector tradicional" y "sus formas de organización empresarial apropiadas", por su calidad de factor de absorción de mano de obra, su potencial para la reducción de las desigualdades y la heterogeneidad estructural, si con el acceso a las tecnologías adecuadas logra "un considerable incremento de la productividad"; $h$ ) "tecnología adecuada", "apropiada" o "intermedia", que se caracteriza "por una mayor utilización de la mano de obra [...] una utilización óptima de los recursos locales y una mayor capacidad de eficiencia en pequeñas escalas productivas"; $i$ ) "consideración a los problemas del medio ambiente", sin perder de vista la satisfacción de las necesidades humanas (incluyendo aquí el empleo), de acuerdo con enfoques de ecodesarrollo, y $j$ ) "autonomía colectiva", que concreta la collective self-reliance en "propuestas de no pagar colectivamente la realmente impagable deuda externa".

Dejando al margen los matices, que serán objeto de una investigación posterior, podemos afirmar que, tanto en los principios contenidos en los dos Planes Nacionales de Desarrollo (2009-2013 y 2013-2017) como luego en las propuestas operativas de política pública, la corriente socialista del Buen Vivir, como estilo de desarrollo que buscaba otro desarrollo, fue coherente con todos los puntos del decálogo, con la excepción parcial de los puntos 3 y 9 y el total del 5 . El otro desarrollo tuvo así una influencia directa e indirecta en el Buen Vivir, pero también encontró sus límites en el punto que Moreno (1985, p. 352) señaló al afirmar que "la aplicabilidad del enfoque requiere condiciones que no resultan fácilmente imaginables sin una previa transformación social radical que permitiera imponer a los sectores dominantes los intereses mayoritarios de la comunidad". Por tanto, en las fuentes ideacionales del Buen Vivir, como política pública inspirada en un estilo de desarrollo, encontramos antecedentes de ideología socialista, con destacados perfiles humanistas, comunitarios e internacionalistas, que son previos a la herencia recibida (y reconocible) por el Buen Vivir a través del concepto de desarrollo a escala humana.

En su trabajo sobre las ideas en acción que se generaron en el entorno de las sucesivas décadas del desarrollo de la ONU, Jolly et al. (2009, p. 
298) señalan que "las ideas son como invenciones", que permanecen latentes hasta que en las circunstancias propicias alguien las intenta poner en práctica, como "viejas ideas en un nuevo disfraz". Una gran parte de los debates sobre el desarrollo que han tenido lugar en América Latina en lo que va del siglo XXI (Sankey y Munck, 2017) están marcados por esas ideas asociadas a las propuestas alternativas de otro desarrollo durante las primeras décadas del desarrollo de la ONU. Hay mucho que aprender de ellas. Es hora de que tales propuestas alternativas empiecen a tomarse en serio por medio de la rigurosa reconstrucción histórica del pensamiento económico latinoamericano, reconstrucción que a juzgar por el modesto aporte historiográfico de América Latina al pensamiento económico global (Barnett, 2015), está en su fase inicial de redescubrimiento y actualización de su vigencia.

\section{LISTA DE REFERENCIAS}

ARndT, H. (1989). Economic development. The history of an idea. Chicago: University of Chicago Press.

BARNETT, V. (ed.) (2015). Routledge handbook of the history of global economic thought. Nueva York: Routledge.

CARdoso, F. H. (1961). La distribución de la renta y el desarrollo económico. Desarrollo Económico, 1(1), 35-114.

Cardoso, F. H. (1980). El desarrollo en el banquillo. Comercio Exterior, 30(8), 846-860.

Caria, S. y Domínguez, R. (2014). El porvenir de una ilusión: la ideología del Buen Vivir. América Latina Hoy. Revista de Ciencias Sociales, 67, 139-163.

Caria, S. y Domínguez, R. (2016). Ecuador's Buen vivir. A new ideology for development. Latin American Perspectives, 43(1), 18-33.

Centro de Desarrollo [Cendes] (1969). Estilos de desarrollo. El Trimestre Económico, 36(144-144), 517-576.

CHick, V. (2013). Economics and the good life: Keynes and Schumacher. Economic Thought, 2(2), 33-45.

Comisión Económica para América latina [CePAl] (1981). América Latina en la Nueva Estrategia Internacional del Desarrollo (metas y objetivos). El Trimestre Económico, 48(190-192), 444-476.

Commoner, B. (1971). The closing circle. Nature, man and technology. Nueva York: Alfred A. Knopf.

Commoner, B. (1974). Dos enfoques de la crisis ambiental. Comercio Exterior, 24(3), 264-280.

Department of Economic And Social AfFairs (1962). The United Nations development decade: Proposals for action. Nueva York: United Nations. 
Domínguez, R. (2013). José Luis Sampedro (1917-2013), pionero de los Estudios del Desarrollo. Revista Iberoamericana de Estudios del Desarrollo, 2(1), 119-125.

Domínguez, R. (2016). En los pliegues de la historia: Cooperación Sur-Sur y procesos de integración en América Latina y el Caribe. Estudos Internacionais: Revista Relações Internacionais, 4(2), 57-77.

Domínguez, R., CARia, S. y León, M. (2017). Buen Vivir: Praise, instrumentalization, and reproductive pathways of Good Living in Ecuador. Latin American and Caribbean Ethnic Studies, 12(2), 133-154.

ECONOMic COMmission fOr LATIN AMERICA [ECLA] (1964). Popular participation and principles of community development in relation to the acceleration of economic and social development. Economic Bulletin of Latin America, 9(2), 225-255.

Economic Commission for LATin America [ECLA] (1973). The Quito appraisal. A review, adopted at the fifteenth session of ECLA as resolution 32O(XV), of the progress made in the first two years of the International Development Strategy. Santiago: Economic Commission for Latin America/Instituto Latinoamericano de Planificación Económica y Social. Recuperado de http://repositorio.cepal.org/handle/11362/35526.

EmmeriJ, L., Jolly, R. y WeIss, T. (2005). Economic and social thinking at the UN in historical perspective. Development and Change, 36(2), 211-235.

EspinOzA, J.G. (1988). Otro desarrollo, otra vida. ¿Fin de la civilización del egoísmo? Nueva Sociedad, 42, 72-80.

ESTUDOS AVANÇADOS (2004). Experiências internacionais de um cientista inquieto. Entrevista com Ingnacy Sachs. Estudos Avançados, 18(52), 353-372.

Fundación DAG HAMmARSKÖLD [DH] (1975). Qué hacer: otro desarrollo. Informe para la VII Sesión Extraordinaria de la Asamblea General de las Naciones Unidas. Upsala: Autor.

Furtado, C. (1966). Hacia una ideología del desarrollo. El Trimestre Económico, 33(101103), 379-391.

Furtado, C. (1974). El mito del desarrollo y el futuro del Tercer Mundo. El Trimestre Económico, 41(162-162), 407-416.

Furtado, C. (1984). El desarrollo como proceso endógeno. Ola Financiera, 8, 170-193.

Gosh, B. N. (2012). Beyond Ghandian Economics. Towards a Creative Deconstruction. Nueva Delhi: SAGE.

Graciarena, J. (1976). Poder y estilos de desarrollo. Una perspectiva heterodoxa. Revista de la CEPAL, 1, 173-193.

Hidalgo-Capitán, A. L. (2012). Seis debates abiertos sobre el sumak kawsay. Íconos. Revista de Ciencias Sociales, 48, 25-40.

Hirschman, A. (1961): Ideologies of economic development in Latin America. En Latin America Issues: Essays and Comments (pp. 3-42). Nueva York: Twentieth Century Fund.

Jolly, R., Emmerij, L., Ghai, D. y Lapeyre, F. (2009). UN contributions to development thinking and practice. Bloomington: Indiana University Press.

Keynes, J. M. (1931). Essays in persuasion. Nueva York: W. W. Norton. 
KISSINGER, H. (1976). UNCTAD IV: Expanding cooperation for global economic development. The Department of State Bulletin, 74(1927), 657-672.

KoeHler, G. (2015). Seven decades of "development", and now what. Journal of International Development, 27(6), 733-751.

Lebowitz, M. A. (2009). The path to human development: Capitalism or socialism. Monthly Review, 60(9). Recuperado de http://monthlyreview.org/2009/02/01/ the-path-to-human-development-capitalism-or-socialism/

LefF, E. (1978). Falacias y aciertos del ecodesarrollo. Comercio Exterior, 28(3), 304-308.

León, M. y Domínguez, R. (2017). Políticas de desmercantilización de la Revolución Ciudadana en Ecuador, contradicciones y tensiones. Revista del CLAD, 68, 135-168.

LOBO, F. (1983). Teoría y política del desarrollo económico en el último cuarto del siglo Xx. Nuevo Orden Económico Internacional y estrategia de las necesidades básicas. El Trimestre Económico, 50(199-193), 1507-1533.

Love, J. L. (1994). Economic ideas and ideologies in Latin America since 1930. En L. Bethell (ed.), The Cambridge history of Latin America, volume VI. Latin America since 1930: Economy, society and politics. Part I, Economy and society (pp. 393-460). Nueva York: Cambridge University Press.

Marx, K. (1979). Crítica del Programa de Gotha. Moscú: Editorial Progreso.

MaX-Neef, M. (1982). La economía descalza. Señales desde el mundo invisible. Montevideo: Editorial Nordan.

Max-Neef, M., Elizalde, A. y Hopenhayn, M. (1986). Desarrollo a escala humana. Una opción para el futuro. Santiago: CEPAUR y Fundación Dag Hammarskjöld.

Minteguiaga, A. y Ubasart, G. (2015). Caminando hacia el buen vivir. El reto de definir el régimen de bienestar. Revista Theomai. Estudios Críticos sobre Sociedad y Desarrollo, 32, 57-75.

Mishan, E. J. (1960). Review of The Economics of Underdevelopment. Economica, 27(106), 192-194.

Moreno, J. A. (1985). El "otro desarrollo": una nota sobre su viabilidad. El Trimestre Económico, 52(206-2), 327-356.

Nerfin, M. (1979). Introduction. En M. Nerfin (ed.), Another development: Approaches and strategies (pp. 9-18). Uppsala: Dag Hammarskjöld Foundation.

Pérez-Caldentey, E. y Vernengo, M. (2016). Reading Keynes in Buenos Aires: Prebisch and the dynamics of capitalism. Cambridge Journal of Economics, 4O(6), 1725-1741.

PInTO, A. (1976). Notas sobre estilos de desarrollo en América Latina. Revista de la CEPAL, 1, 97-128.

Prebisch, R. (1961). Desarrollo económico, planeamiento y cooperación internacional. Santiago de Chile: CEPAL.

Programa de las Naciones Unidas para el Medio Ambiente/Conferencia de las Naciones Unidas sobre Comercio y Desarrollo [Pnuma/unctad] (1974). Declaración de Cocoyoc. Comercio Exterior, 25(1), 20-24. 
Pronk, J. (1978). Redefinición de intereses comunes. Relaciones Norte-Sur, Nueva Sociedad, 36, 77-88.

Rist, G. (2007). Development as a buzzword. Development in Practice, 17(4-5), 485-491.

Robinson, J. ([1971] 2015). La segunda crisis de la teoría económica. Revista de Economía Crítica, 19, 204-213.

SACHS, I. (1974a). Ecodesarrollo: un aporte a la definición de estilos de desarrollo para América Latina. Estudios Internacionales, 25, 57-77.

SACHS, I. (1974b). Ambiente y estilos de desarrollo. Comercio Exterior, 24(4), 360-368.

SACHS, I. (1977). El ambiente humano. En J. TINBERGERN (coord.), Reestructuración del orden internacional. Informe al Club de Roma (448-466). México: Fondo de Cultura Económica.

SACHS, I. (1980). Ecodesarrollo. Concepto, aplicación, implicaciones. Comercio Exterior, 30(7), 718-725.

SAMATER, I. M. (1984). From "growth" to "basic needs". The evolution of development theory. Monthly Review, 36(5), 1-13.

SAmpedro, J. L. (1980). Desarrollo económico, en R. Martínez (dir.), Economía Planeta. Diccionario Enciclopédico (vol. 3, pp. 352-367). Barcelona: Planeta.

Sampedro, J. L. (1983). Triple nivel, doble estrategia y otro desarrollo. El Trimestre Económico, 50(199-3), 1655-1675.

SAmpedro, J. L. (1987). Aprendizajes de un metaeconomista. Economistas, 26, 36-42.

SAmpedro, J. L. (2009). Economía humanista. Algo más que cifras. Barcelona: Debate.

SAnkey, K. y MuncK, R. (2017). Rethinking development in Latin America: The search for alternative paths in the twenty-first century, Journal of Developing Societies, 32(4), 334-361.

SeErs, S. (1969). The meaning of development. IDS Communication, 44. Recuperado de http://www.ids.ac.uk/files/dmfile/themeaningofdevelopment.pdf

SejENOVICH, H. (2011). La calidad de vida, la cuestión ambiental y sus interrelaciones. En V. FARAH y L. VASAPOLlO (coords.), Vivir bien ¿Paradigma no capitalista? (pp. 209-230). La Paz: CIDES-UMSA.

Singh, R. P. B. (2006). Mohandas (Mahatma) Ghandi. En D. Simon (ed.), Fifty key thinkers on development (pp. 106-111). Nueva York: Routledge.

Stewart, F. (2006). Basic needs. En D. A. Clark (ed.), The elgar companion to development studies (pp. 14-18). Chentelham: Edward Elgar.

Sunkel, O. (1980). Introducción. La interacción entre los estilos de desarrollo y el medio ambiente en América Latina. En O. Sunkel (comp.), Estilos de desarrollo y medio ambiente en América Latina (pp. 9-64). México: Fondo de Cultura Económica.

Tinbergen, J. (coord.) (1977). Reestructuración del orden internacional. Informe al Club de Roma. México: Fondo de Cultura Económica.

Veblen, T. (1898). The Instinct of Workmanship and the Irksomness of Labor. American Journal of Sociology, 4(2), 187-201.

Veblen, T. (2007). The theory of the leisure class. Oxford: Oxford University Press. 
Weisbrot, M., Johnston, J. y Merling, L. (2017). Una década de reformas: políticas macroeconómicas y cambios institucionales en Ecuador y sus resultados. Center for Economic Policy Research, Washington, D. C., Estados Unidos.

Wolfe, M. (1976): Enfoques del desarrollo. ¿De quién y hacia qué? Revista de la CEPAL, 1, 129-172.

Wolfe, M. (1979). Reinventando el desarrollo: utopías de comités y simientes de cambio reales. Revista de la CEPAL, 7, 7-42.

World BANK (1980). World Development Report 1980. Nueva York: Oxford University Press. 